\title{
Kesetimbangan Adsorpsi Zat Warna Methyl Violet Oleh Karbon Aktif Berbasis Limbah Daun Nanas (Ananas comosus $\mathrm{L}$ )
}

\author{
Lanjar, Fatma Indah Riayanti dan Widi Astuti* \\ Departemen Teknik Kimia, Fakultas Teknik, Universitas Negeri Semarang \\ Kampus Sekaran Gunungpati, Semarang, 50229 Indonesia \\ Email : widi_astuti@mail.unnes.ac.id
}

Abstrak

Industri tekstil semakin berkembang seiring dengan pertumbuhan penduduk di Indonesia. Selain memberikan manfaat, industri tekstil memberikan dampak negatif bagi lingkungan akibat penggunaan zat warna sintetis, salah satunya yaitu methyl violet. Apabila limbah tersebut dibuang ke perairan akan menyebabkan rusaknya ekologi lingkungan dan ancaman bagi kesehatan manusia, karena sebagian besar zat warna bersifat sukar terurai (non-bidegradable) dan karsinogenik (Brono, 2010). Salah satu metode yang terbukti efektif untuk menghilangkan zat warna adalah adsorpsi menggunakan karbon aktif. Pada penelitian ini karbon aktif dibuat dari limbah daun nanas dengan aktivator $\mathrm{ZnCl}_{2}$ dan pemanasan gelombang mikro. Selanjutnya, karbon aktif tersebut dikarakteriasi morfologi permukaan menggunakan Scanning Electron Microscopy (SEM), luas permukaan menggunakan Surface Area Analyzer, dan analisis gugus fungsi menggunakan Fourier Transform Infrared (FTIR) spectrometer, dan digunakan untuk menjerap methyl violet di larutan. Hasil penelitian menunjukkan bahwa karbon aktif dari limbah daun nanas yang teraktivasi $\mathrm{ZnCl}_{2}$ menghasilkan pori yang lebih besar dibandingkan dengan karbon tanpa aktivasi serta memiliki gugus fungsi yang dapat menjerap methyl violet. Kondisi optimum untuk adsorpsi adalah pH 5, waktu kontak 90 menit, dan konsentrasi awal $500 \mathrm{mg} / \mathrm{L}$. Model kesetimbangan yang sesuai yaitu menggunakan model isotherm freundlich.

Kata kunci : karbon akti; daun nanas; $\mathrm{ZnCl}_{2}$; microwave; methyl violet

\section{PENDAHULUAN}

Pertumbuhan penduduk di Indonesia setiap tahunnya mengalami peningkatan yang cukup besar. Hal ini mendorong berkembangnya industri tekstil. Selain memberikan banyak manfaat untuk memenuhi kebutuhan sandang di Indonesia, ternyata industri tekstil juga memberikan dampak negatif yaitu pencemaran lingkungan, yang berasal dari penggunaan zat warna sintetis. Salah satu zat warna yang sering digunakan pada industri tekstil adalah methyl violet (Astuti dan Fatin, 2017). Pada umumnya zat warna tersebut tidak seluruhnya dapat terserap ke dalam bahan yang diwarnai dan terbuang sebagai limbah cair. Limbah tersebut jika dibuang di lingkungan perairan akan menyebabkan rusaknya ekologi lingkungan dan ancaman bagi kesehatan manusia. Hal ini dikarenakan sebagian besar zat warna bersifat sukar terurai (non-biodegradable) dan karsinogenik (Brono, 2010).
Berbagai metode dalam pengolahan limbah mengandung zat warna telah banyak dilakukan, diantaranya koagulasi (Yulianto, 2009), penukar ion (Kundari, 2008), dan fotokatalitis $\mathrm{TiO}_{2}$ (Hardeli et al., 2014). Namun metode tersebut memerlukan biaya tinggi sehingga sulit diterapkan di industri kecil dan menengah.

Adsorpsi menggunakan karbon aktif merupakan metode yang paling banyak digunakan, karena metode ini dinilai efektif dan memberikan hasil yang cukup baik (Astuti et al., 2017 \& Astuti et al., 2016). Dewasa ini, limbah biomassa telah digunakan sebagai prekursor dalam pembuatan karbon aktif untuk menekan biaya. Daun nanas mengandung selulosa yang cukup tinggi sebesar 69,5-71,5\% (Hidayat, 2008). Dengan pertimbangan selulosa tinggi yang dimiliki, maka daun nanas dapat digunakan sebagai prekursor pada pembuatan karbon aktif.

Pada penelitian ini dipilih $\mathrm{ZnCl}_{2}$ sebagai aktivator kimia karena memiliki banyak kelebihan 
dibandingan dengan aktivator yang lain. Diantaranya menghasilkan surface area dan volume pori lebih besar, kadar abu yang dihasilkan lebih rendah, dan lebih mudah larut dalam air pada tahap pencucian (Tzong, et al., 2010., T.H. Liou, et al., 2009). Dalam hal ini, jumlah konsentrasi $\mathrm{ZnCl}_{2}$, waktu dan suhu proses aktivasi diduga berpengaruh terhadap kemampuan adsorpsi. Hal ini dipelajari lebih lanjut dalam penelitian ini. Selain itu, teknik pemanasan diduga berpengaruh terhadap karakater karbon aktif yang dihasilkan. Dalam beberapa tahun terakhir, penggunaan gelombang mikro dianggap sebagai metode alternatif yang lebih menjanjikan pada proses pemanasan material. Waktu proses menjadi lebih pendek dibandingkan jika menggunakan furnace sehingga energi yang dibutuhkan juga lebih kecil ( Liu et al., 2016). Pengaruh teknik pemanasan terhadap karakteristik dan kemampuan karbon aktif dalam menjerap methyl violet akan dipelajari lebih lanjut dalam penelitian. Selain itu, kesetimbangan adsorpsi juga dipelajari untuk memperoleh parameter-parameter yang diperlukan pada perancangan proses adsorpsi.

\section{METODOLOGI}

Bahan baku yang digunakan dalam penelitian ini yaitu limbah daun nanas, $\mathrm{ZnCl}_{2}, \mathrm{HCl}$, $\mathrm{NaOH}$, dan aquades. Sementara alat yang digunakan yaitu seperangkan alat microwave.

Daun nanas dicuci dengan air dan dipotong kecil - kecil, lalu dikeringkan dibawah sinar matahari dan dioven pada suhu $110^{\circ} \mathrm{C}$ hingga beratnya konstan. Proses karbonisasi dilakukan menggunakan selama 1 jam pada suhu $500^{\circ} \mathrm{C}$. Proses aktivasi dilakukan menggunakan $\mathrm{ZnCl}_{2}$ dengan perbandingan $\mathrm{ZnCl} 2$ : karbon $(\mathrm{g} / \mathrm{g})$ sebesar 1:1, 2:1, dan 3:1 selanjutnya dipanaskan menggunakan radiasi gelombang mikro dengan daya input 600 watt selama 6 menit. Karbon aktif yang sudah diaktivasi kemudian dicuci dengan $\mathrm{HCl}$ dan dibilas dengan aquades hingga $\mathrm{pH}$ netral, selanjutnya dikeringkan dalam oven pada suhu $1100 \mathrm{C}$ hingga beratnya konstan. Karbon aktif yang telah disintesis kemudian dikarakterisasi morfologi permukaan menggunakan Scanning Electron Microscope (SEM) dan gugus fungsi menggunakan Fourier Transform Infrared (FTIR) Spectrometer.
Proses adsorpsi dilakukan dengan berbagai variasi ph $(3,5,7,9$, dan 11), konsentrasi awal methyl violet $(10,20,30,40,50,60,70,80,90,100$, 200, 300, 400, dan 500) ppm.

\section{HASIL DAN PEMBAHASAN}

\section{Karakterisasi Karbon dan Karbon Aktif Daun Nanas}

Berdasarkan Gambar 1a terlihat bahwa karbon tanpa aktivasi telah memiliki pori, namun ukuran pori yang dimiliki masih kecil dan kedalaman pori yang masih rendah. Selain itu, pori - pori masih tertutupi oleh senyawa pengotor akibat proses karbonisasi menggunakan furnace. Sementara, karbon aktif dari limbah daun nanas pada Gambar 1b memiliki ukuran pori yang lebih besar dan lebih banyak pori yang terbentuk. Pori pori yang terbentuk merupakan hasil dari penguapan $\mathrm{ZnCl}_{2}$ selama proses pemanasan menggunakan microwave (Mohanty et al, 2005). $\mathrm{ZnCl}_{2}$ terevaporasi dan terdekomposisi menjadi zink dan chlorine, dimana kondisi tersebut menyebabkan proses pembentukan pori dan perbesaran ukuran pori (Zhang et al, 2009). Mekanisme perbesaran ukuran pori yaitu dengan cara $\mathrm{ZnCl}_{2}$ meninggalkan ruangan yang sebelumnya telah terisi olehnya sehingga terbentuk pori pada karbon aktif yang lebih besar (Mohanty et al, 2005). Proses pemanasan juga lebih merata sehingga ukuran pori lebih seragam. Proses aktvasi menggunakan microwave dialiri gas $\mathrm{N}_{2}$ untuk menghilangkan zat pengotor yang masih menempel pada permukaan pori karbon aktif.

Analisis gugus fungsi dilakukan untuk mengetahui ketersediaan gugus fungsi, yang dilakukan pada panjang gelombang 4000 - 370 $\mathrm{cm}^{-1}$. Hasil analisis tersji pada Gambar 2.

Data pada Gambar 2a menunjukkan adanya puncak serapan pada bilangan gelombang $3787.97 \mathrm{~cm}^{-1}, 3700,11 \mathrm{~cm}^{-1}$, dan $3407.11 \mathrm{~cm}^{-1}$ pada karbon tanpa aktivasi yang mengindikasikan adanya gugus $\mathrm{OH}$. Sementara, pada karbon teraktivasi $\mathrm{ZnCl}_{2}$ Gambar $2 \mathrm{~b}$ terlihat adanya puncak serapan pada bilangan gelombang $3785.34 \mathrm{~cm}^{-1}, 3704.19 \mathrm{~cm}^{-1}, 3661.87 \mathrm{~cm}^{-1}$ dan $3431.48 \mathrm{~cm}^{-1}$ yang mengindikasikan adanya penambahan gugus $\mathrm{O}-\mathrm{H}$. Gambar 2c menunjukkan adanya puncak serapan pada bilangan gelombang $3784.0 \mathrm{~cm}^{-1}, 3697.29 \mathrm{~cm}^{-1}$, 
$3661.42 \mathrm{~cm}^{-1}$, dan $3430.34 \mathrm{~cm}^{-1}$ yang menujukkan adanya gugus $\mathrm{O}-\mathrm{H}$ namun nilainya menurun dan terlihat pada gambar semakin dangkal, ini berarti gugus $\mathrm{O}-\mathrm{H}$ semakin berkurang setelah adsorpsi karena terisi oleh gugus methyl violet. Hal tersebut ditandai dengan adanya gugus $\mathrm{CH}_{3}$ pada puncak serapan $1369.98 \mathrm{~cm}^{-1}$.

Pita serapan $1582.96 \mathrm{~cm}^{-1}$ pada karbon sebelum aktivasi menujukkan adanya gugus aromatik dan pada karbon setelah aktivasi gugus aromatik mengalami penambahan jumlah pada puncak serapan $1598.15 \mathrm{~cm}^{-1}$ dan $1437 \mathrm{~cm}^{-1}$. Hal tersebut terjadi karena adanya pembentukan struktur pembentukan aromatik baru pada karbon. Sedangkan pada karbon setelah adsorpsi puncak serapan $1589.94 \mathrm{~cm}^{-1}$ yang menujukkan adanya gugus aromatik namun mengalami penurunan dikarenakan adanya adsorpsi methyl violet. Gugus aromatik merupakan karakteristik selulosa dan hemiselulosa.

\section{Adsorpsi Methyl Violet}

Pengaruh $\mathrm{pH}$ Larutan

Kondisi $\mathrm{pH}$ optimum adalah kondisi $\mathrm{pH}$ dimana pada $\mathrm{pH}$ tersebut jumlah methyl violet yang terjerap adsorben mencapai nilai maksimal. Untuk mengetahui $\mathrm{pH}$ optimum dilakukan adsorpsi oleh karbon dengan variasi $\mathrm{pH} \mathrm{1,3,5,7,}$ 9, dan 11 dengan variasi konsentrasi $\mathrm{ZnCl}_{2}$ 10\%, $20 \%$, dan 30\%. Grafik pengaruh pH adsorpsi methyl violet dapat dilihat pada Gambar 3.

Data pada Gambar 3 menujukkan bahwa pada $\mathrm{pH} 1$ hingga $\mathrm{pH} 5$ jumlah zat warna yang teradsorpsi mengalami peningkatan, namun pada

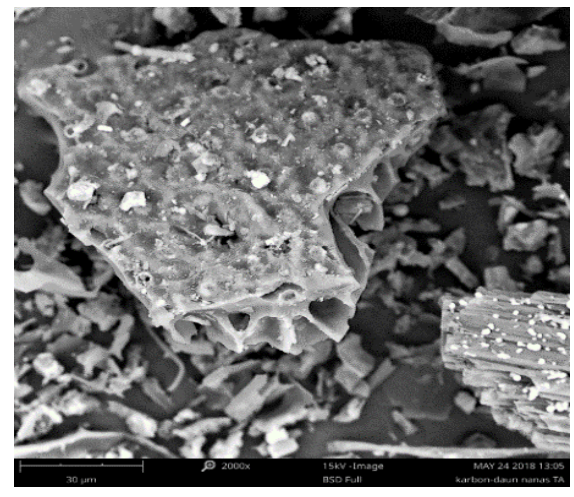

(a)

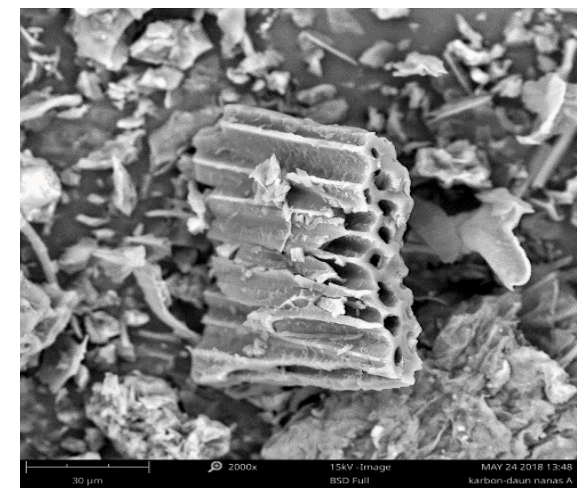

(b)

Gambar 1. SEM (a) Karbon tanpa aktivasi dan (b) Karbon teraktivasi $\mathrm{ZnCl}_{2}$

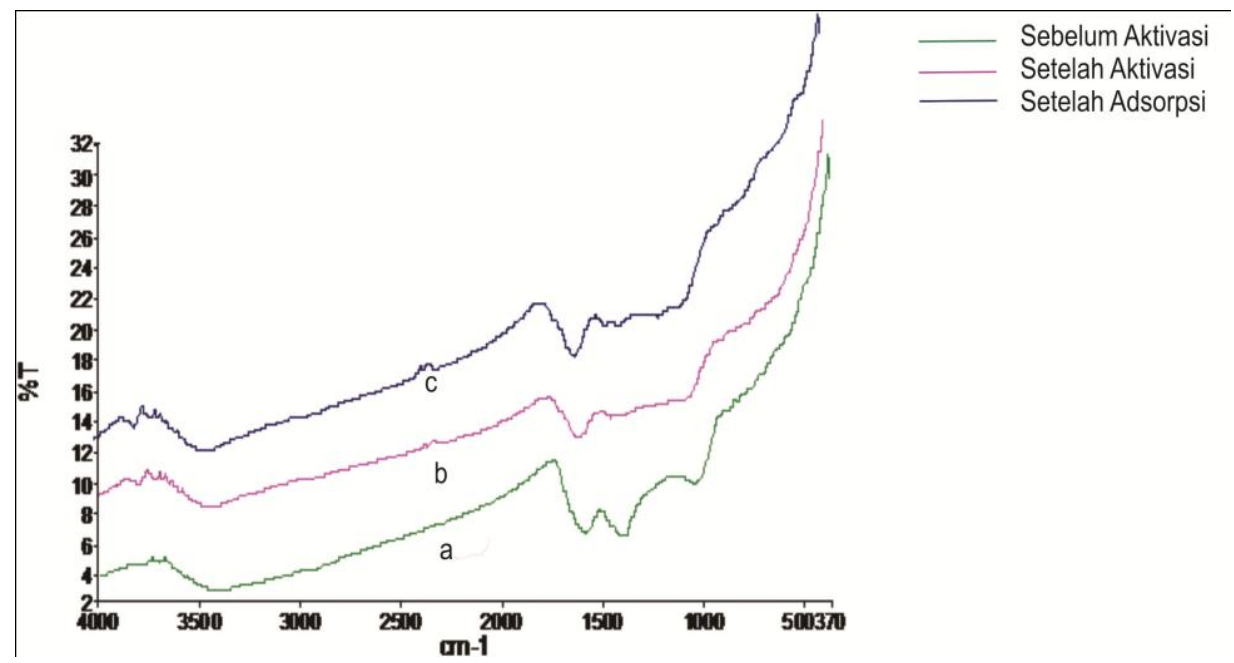

Gambar 2. Kurva Spektrum FTIR 
$\mathrm{pH} 5$ hingga $\mathrm{pH} 11$ mengalami penurunan., dengan jumlah methyl violet tertinggi $\mathrm{pH} 5$ sebesar 99,45 \% pada karbon aktif teraktivasi 30\% $\mathrm{ZnCl}_{2}$. Dari Gambar 4.4 terlihat bahwa karbon aktif teraktivasi $30 \% \quad \mathrm{ZnCl}_{2}$ dapat menjerap methyl violet lebih tinggi daripada karbon aktif teraktivasi $10 \% \quad \mathrm{ZnCl}_{2}$ dan $20 \% \quad \mathrm{ZnCl}_{2}$. Hal ini dapat disimpulkan bahwa penggunaan $\mathrm{ZnCl}_{2}$ dengan konsentrasi $30 \%$ memeberikan hasil yang paling optimum.

Pengaruh Konsentrasi Awal Larutan Zat Warna Methyl Violet

Pengaruh konsentrasi awal larutan dipelajari pada variasi konsentrasi 10, 20, 30, 40,
50, 60, 70, 80, 90, 100, 200, 300, 400, dan 500 $\mathrm{mg} / \mathrm{L}$ yang hasilnya tersaji pada Gambar 4 .

Gambar 4 menunjukkan jumlah methyl violet teradsorpsi oleh karbon daun nanas teraktivasi $10 \%, 20 \%$, dan $30 \% \mathrm{ZnCl}_{2}$. Pada konsentrasi awal $10 \mathrm{mg} / \mathrm{L}$ hingga $700 \mathrm{mg} / \mathrm{L}$ jumlah methyl violet teradsorpsi cenderung mengalami peningkatan sebanding dengan meningkatnya konsentrasi awal larutan, hingga pada konsentrasi awal 500 mg/L terjadi kesetimbangan. Kenaikan konsentrasi awal larutan memberikan jumlah methyl violet teradsorpsi juga semakin besar. Hal ini karena semakin tinggi konsentrasi awal larutan maka kekuatan gaya dorong (driving force) juga semakin besar. Jumlah mehyl violet teradsorpsi

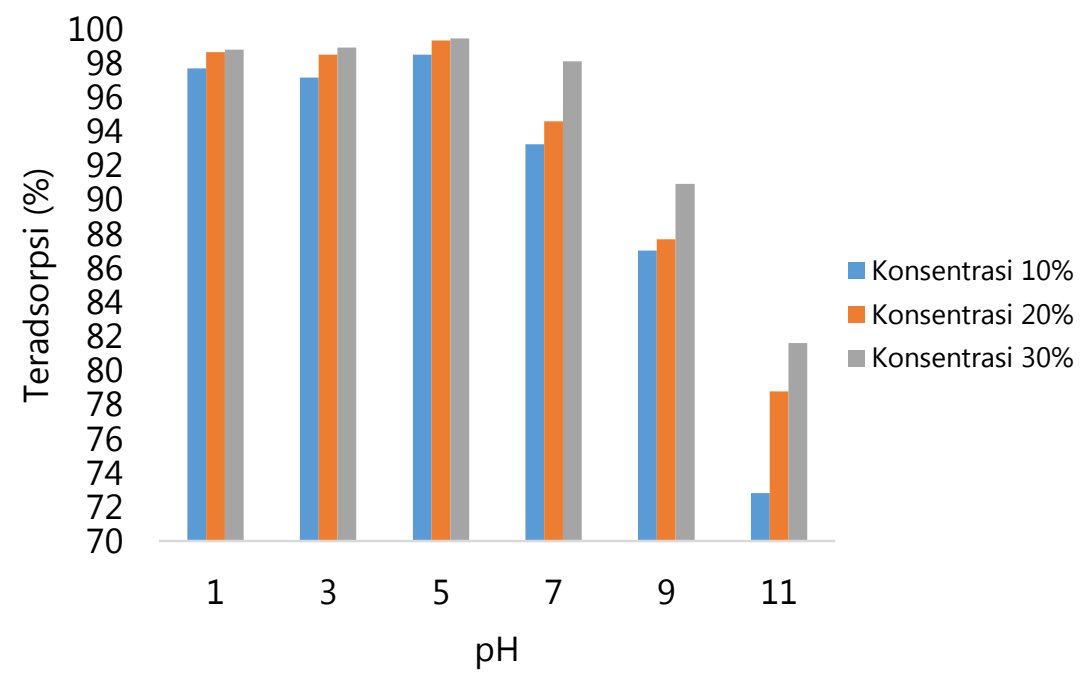

Gambar 3. Pengaruh $\mathrm{pH}$ terhadap persentase methyl violet teradsorpsi

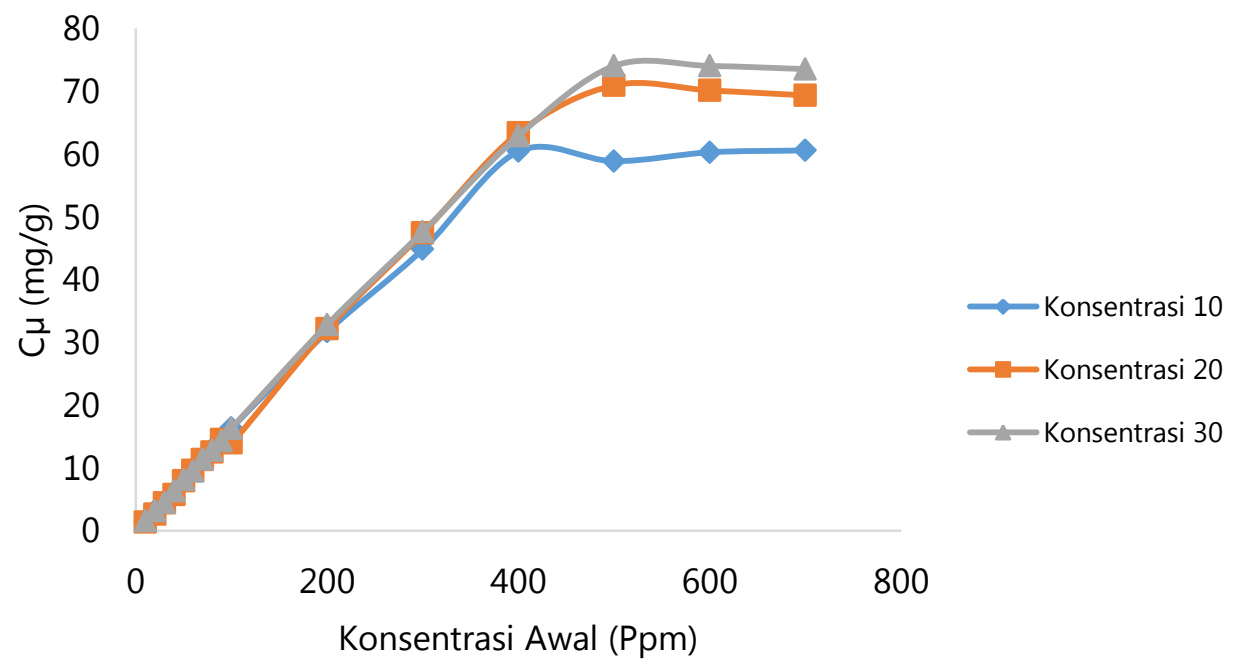

Gambar 4. Pengaruh Konsentrasi Awal Methyl Violet terhadap Jumlah Methyl Violet Teradsorpsi 
oleh karbon aktif daun nanas teraktivasi 30\% $\mathrm{ZnCl}_{2}$ dengan konsentrasi awal larutan $700 \mathrm{mg} / \mathrm{L}$ sebesar 73,5563 mg/g.

\section{Isoterm Adsorpsi}

Isotherm adsorpsi diperlukan untuk mengetahui kapasitas adsorpsi yang sangat penting dalam perancangan suatu proses adsorpsi. Model isotherm adsorpsi diperoleh dari pengolahan data variasi konsentrasi awal larutan methyl violet yang diadsorpsi menggunakan karbon aktif. Isotherm adsorpsi yang digunakan untuk menggambarkan proses adsorpsi fase cair adalah persamaan Langmuir dan persamaan Freundlich.

Isoterm Langmuir

Persamaan isoterm langmur :

$C_{\mu}=C_{\mu m} \frac{K_{L} C_{e}}{1+K_{L} C_{e}}$
Persamaan tersebut secara linier:

$\frac{C_{e}}{C_{\mu}}=\frac{1}{C_{\mu m} K_{L}}+\frac{1}{C_{\mu m}} C_{e}$

Persamaan Isotherm Langmuir dapat dicari dengan membuat grafik hubungan $\mathrm{Ce}$ versus $\mathrm{Ce} / \mathrm{C} \mu$ diperoleh garis lurus dengan tangen arah $\frac{1}{C_{\mu m}}$ dan titik potong pada sumbu y dengan ordinat $\frac{1}{C_{\mu m} K_{L}}$. Kurva linier persamaan Langmuir membentuk persamaan garis $y=4,854 x+0,2407$ dengan $R^{2}=0,967$ yang terlihat pada Gambar 5 . Dari persamaan tersebut diperoleh $\mathrm{C} \mu \mathrm{m}=0,2060$ $\mathrm{mmol} / \mathrm{g}$ dan $\mathrm{K}_{\mathrm{L}}=20,1661 \mathrm{~L} / \mathrm{mmol}$.

Isoterm Freundlich

Persamaan isoterm Freundlich untuk cairan dapat dituliskan sebagai berikut:

$C_{\mu}=k_{F} C_{e}^{1 / n}$

Konstanta Freunlich dapat diperoleh secara linear: $\log C_{\mu}=\log k_{F}+{ }_{n}^{1} \log C_{e}$

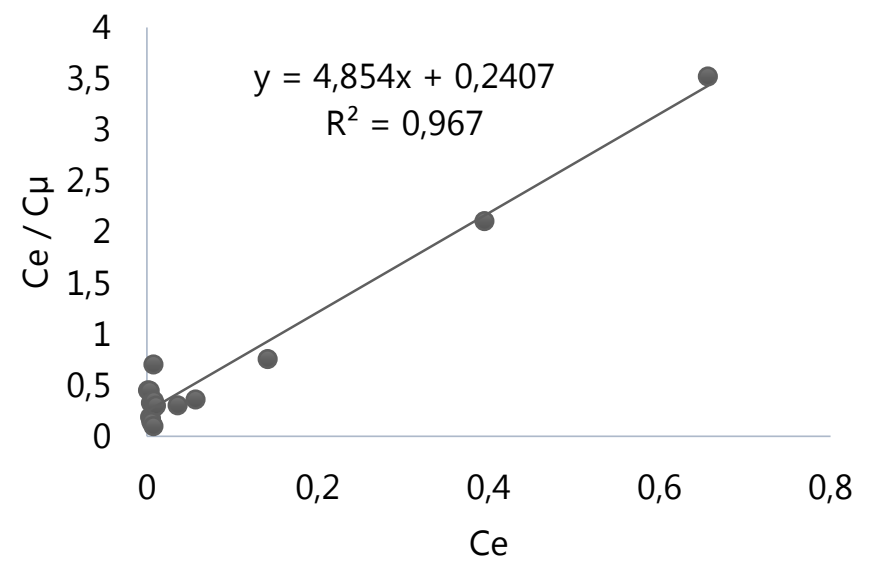

Gambar 5. Isoterm Langmuir Adsorpsi Methyl Violet

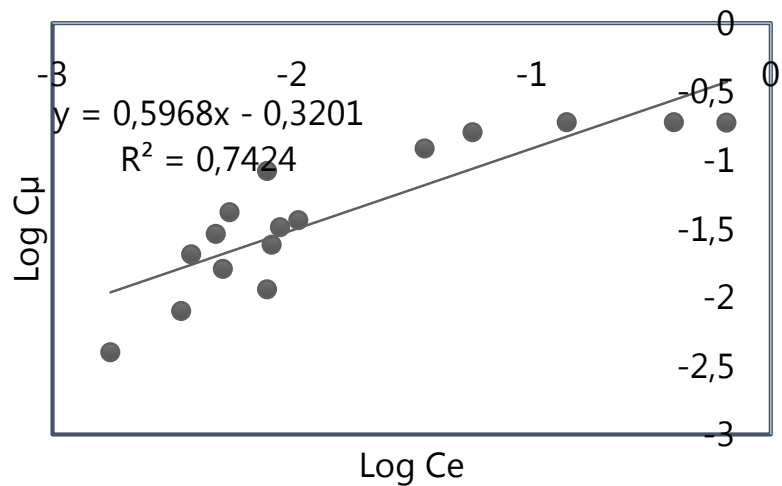

Gambar 6. Isoterm Freundlich Adsorpsi Methyl Violet 
Persamaan Isoterm Freundlich dapat dicari dengan membuat grafik hubungan antara $\log \mathrm{Ce}$ dan $\log \mathrm{C} \mu$ diperoleh garis lurus dengan tangen arah $\frac{1}{n}$ dan titik potong pada sumbu $y$ dengan ordinat log $\mathrm{k}_{\mathrm{F}}$ sehingga nilai $\mathrm{k}_{\mathrm{F}}$ dan $\mathrm{n}$ dapat ditentukan. Kurva linier persamaan Freundlich membentuk persamaan garis $\mathrm{y}=$ $0,5968 x-0,3201$ dengan $R^{2}=0,7424$ yang terlihat pada Gambar 6. Dari persamaan garis tersebut didapat tetapan $K_{F}=0,1809$ dan $n=1,6756$. Berdasarkan grafik pada Gambar 5 dan 6 terlihat bahwa isoterm langmuir memiliki korelasi $\left(R^{2}\right)$ yang lebih besar dibandingkan isoterm freundlich. Maka dari itu dapat disimpulkan bahwa model isotherm langmuir lebih cocok digunakan untuk sistem adsorpsi methyl violet oleh karbon aktif.

\section{KESIMPULAN}

Penelitian ini memanfaatkan limbah daun nanas sebagai adsorben dengan penambahan $\mathrm{ZnCl}_{2}$ sebagai activator. Kondisi optimum adsorpsi methyl violet yaitu $\mathrm{pH} \mathrm{5,} \mathrm{waktu} \mathrm{optimum} \mathrm{pada}$ kontak 90 menit dan memenuhi isotherm Langmuir.

\section{DAFTAR PUSTAKA}

Astuti, W., \& Fatin, D.M. 2017. Adsorption of Methyl Violet Dye by Thermally Modified Ceiba Pentandra Sawdust. J. Bahan Alam Terbarukan. 6(2):183 - 189.

Astuti, W., Sulistyaningsih, T. \& Maksiola, M. 2016. Chemically Modified Kapok Sawdust as
Adsorbent of Methyl Violet Dye from Aqueous Solution. J. Teknologi. 78(9): 35-42.

Astuti, W., Sulistyaningsih, T., \& Maksiola, M. 2017. Equilibrium and Kinetics of Adsorption of Methyl Violet from Aqueous Solutions using Modified Ceiba Pentandra Sawdust. Asian J. Chem. 29(1):133-138.

Brono, H. 2010. Mewarnai Batik Dengan Indigofera. Jakarta: Universitas Indonesia.

Hardeli, Ramadhani, A., Kurniawati, D., Andriko, N. \& Sanjaya, H. 2014. Degradasi Methyl Violet dan Methylen Blue Oleh Fookatalis $\mathrm{TiO}_{2}$. Eksakta. 1:107-114

Hidayat, P. 2008. Teknologi Pemanfaatan Serat Daun Nanas sebagai Alternatif Bahan Baku Tekstil. Teknoin. 13:31-35.

Kundari, N. \& Wiyunati, S. 2008. Tinjauan Kesetimbangan Adsorpsi Tembaga dalam Limbah Pencuci PCB dengan Zeolit. Sekolah Tinggi Teknologi Nuklir-Batan.

Liou. T.H. 2004. Kinetics Study of Thermal Decomposition of Electronic Packaging Material. Chem. Eng. J. 98(1-2):39-51.

Liou, T.H. 2010. Development of Mesoporous Structure and High Adsorption Capacity of Biomass-Based Activated Carbon by Phosphoric Acid and Zinc Chloride Activation. Chem. Eng. J. 158(2):129-142.

Yulianto, A., Hakim, L., Purwaningsih, I. \& Pravitasari, V.A., 2009. Pengolahan limbah cair industri batik pada skala laboratorium dengan menggunakan metode elektrokoagulasi. J. Teknol. Ling. Univ. Trisakti, 5(1):6-11. 